\title{
Genetic mapping and transcription analyses of resistance gene loci in potato using NBS profiling
}

\author{
Bart Brugmans $\cdot$ Doret Wouters $\cdot$ Hans van Os $\cdot$ Ronald Hutten $\cdot$ \\ Gerard van der Linden · Richard G. F. Visser · Herman J. van Eck • \\ Edwin A. G. van der Vossen
}

Received: 28 March 2008 / Accepted: 15 August 2008 / Published online: 20 September 2008

(c) The Author(s) 2008. This article is published with open access at Springerlink.com

\begin{abstract}
NBS profiling is a method for the identification of resistance gene analog (RGA) derived fragments. Here we report the use of NBS profiling for the genome wide mapping of RGA loci in potato. NBS profiling analyses on a minimal set of $\mathrm{F} 1$ genotypes of the diploid mapping population previously used to generate the ultra dense (UHD) genetic map of potato, allowed us to efficiently map polymorphic RGA fragments relative to 10,000 existing AFLP markers. In total, 34 RGA loci were mapped, of which only 13 contained RGA sequences homologous to RGAs genetically positioned at approximately similar positions in potato or tomato. The remaining RGA loci mapped either at approximate chromosomal regions previously shown to contain RGAs in potato or tomato without sharing homology to these RGAs, or mapped at positions not yet identified as RGA-containing regions. In addition to markers representing RGAs with unknown functions, segregating markers were detected that were closely linked to four functional $R$ genes that segregate in the UHD mapping population. To explore the potential of NBS profiling in RGA transcription analyses, RNA isolated from different tissues was used as template for NBS profiling. Of all the fragments amplified approximately $15 \%$ showed putative
\end{abstract}

Communicated by C. Gebhardt.

B. Brugmans $\cdot$ D. Wouters $\cdot$ H. van Os $\cdot$ R. Hutten ·

G. van der Linden · R. G. F. Visser · H. J. van Eck ·

E. A. G. van der Vossen $(\bowtie)$

Wageningen UR Plant Breeding, P.O. Box 386,

6700 AJ Wageningen, The Netherlands

e-mail: edwin.vandervossen@wur.nl

Present Address:

B. Brugmans

Easygene, Nieuwe Kanaal 7m,

6709 PA Wageningen, The Netherlands intensity or absent/present differences between different tissues suggesting putative tissue specific RGA or $R$ gene transcription. Putative absent/present differences between individuals were also found. In addition to being a powerful tool for generating candidate gene markers linked to $R$ gene loci, NBS profiling, when applied to cDNA, can be instrumental in identifying those members of an $R$ gene cluster that are transcribed, and thus putatively functional.

\section{Introduction}

Plants are under constant attack from a great variety of pathogens. In defense, they have evolved an immune response that is for the greatest part governed by specificity determinants called resistance $(R)$ genes. This simple yet sophisticated immune system involves an allele-specific genetic interaction between the products of host $R$ genes and pathogen avirulence (Avr) genes (Flor 1971; Keen 1990). Identification of numerous functional $R$ genes from model and crop species has revealed that the majority of these genes encode cytoplasmic proteins with nucleotide binding site (NBS) and leucine rich repeat (LRR) domains and that they often belong to complex loci comprised of arrays of related genes (reviewed in Martin et al. 2003). Based on the genome sequences of Arabidopsis and rice (TAGI 2000; Goff et al. 2002; Meyers et al. 2002) the majority of plant genomes are estimated to contain hundreds of NBS-LRR genes.

Conservation of several structural motifs within the NBS domain encoded by plant $R$ genes has prompted the development of homology-based approaches aimed at identification of structurally related sequences, termed $R$ gene analogues (RGAs) (Kanazin et al. 1996; Yu et al. 1996; Leister et al. 1996; Aarts et al. 1998; Shen et al. 1998; Pan 
et al. 2000; van der Linden et al. 2004). Cosegregation of specific RGAs and $R$ loci and/or quantitative trait loci (QTL) involved in disease resistance has been reported (Hunger et al. 2002; Kuhn et al. 2003), suggesting that NBS profiling can be a powerful tool for the development of markers linked to resistance loci.

Although the use of degenerate primers to amplify new RGAs is useful to detect and clone $R$ genes, this method is often laborious, involving the cloning and sequencing of the fragments, after which a polymorphism has to be identified before the fragment can genetically be mapped. Motif directed fingerprinting techniques which combine the advantage of a neutral marker system with a bias towards candidate genes are a better option. The use of degenerate primers that target NBS specific motifs in combination with adapter based amplification techniques generates complex fingerprinting patterns containing several RGA derived fragments (Hayes et al. 2000; van der Linden et al. 2004). By applying NBS based profiling techniques on individuals of an F1 mapping population, the genetic variation at RGA loci is sampled, resulting in the direct mapping of these fragments relative to other genetic markers or $R$ loci that segregate in the mapping population (Calenge et al. 2005). By comparing the genetic position and sequence of these mapped fragments with sequences and/or map positions of known $R$ genes from potato and tomato (Leister et al. 1996; Pan et al. 2000; Gebhardt and Valkonen 2001), new $R$ gene clusters or markers tightly linked to known resistances can be located.

When using genomic DNA as template for NBS profiling, the identified RGA fragments will be derived from both functional and incomplete or pseudogenes, many of which are probably not transcribed. In contrast, when cDNA is used, all fragments amplified will be derived from genes that are at least transcribed, a first prerequisite for functionality. Similar to DNA, cDNA can also be used to detect single nucleotide polymorphisms (SNP) making it possible to generate fragments and genetically map these fragments relative to a genetic map (Brugmans et al. 2002). NBS profiling on cDNA should give a set of fragments derived from transcribed $R$ genes, provided that the sensitivity of NBS profiling is high enough to detect $R$ genes in a complex mixture of genes. With cDNA as template, one increases the chances of recovering markers derived from true candidate genes, which is of extra interest when cloning $R$ genes from extremely complex loci. In addition, it may be possible to detect differences in $R$ gene transcription between tissues. To date, little is known about tissue specific transcription of $R$ genes. The fact that a single $R$ gene can interfere with pathogens that affect different tissues, as is demonstrated for the $M i$ resistance gene, which in tomato confers resistance to three species of root knot nematodes (Meloidogyne spp.) as well as to the potato aphid Macrosiphum euphorbiae (Vos et al. 1998; Rossi et al. 1998; Milligan et al. 1998) and to both B- and Q-biotypes of whitefly Bemisia tabaci (Nombela et al. 2003), suggests that $R$ genes are transcribed in multiple tissues.

Here we describe an application for NBS profiling to generate $R$ gene derived fragments and genetically map these fragments relative to other markers of the Ultra High Density (UHD) map of potato (Isidore et al. 2003; van Oss et al. 2006). By comparing the sequences and mapping positions of the fragments with known genes, the potential of NBS profiling to generate fragments linked to known $R$ gene clusters and to detect new $R$ gene clusters is evaluated. Furthermore, differences in $R$ gene transcription between tissues and between individuals is demonstrated by performing NBS profiling on cDNAs generated from RNA from different tissues.

\section{Materials and methods}

\section{Plant material and DNA isolation}

For selective mapping purposes a subset of 29 informative genotypes (RHSH\#11, -\#13, -\#34, -\#101, -\#130, -\#138, -\#164, -\#178, -\#179, -\#185, -8, - 11, -24, $-29,-33,-46,-48,-51,-54,-55,-58,-60,-71$, $-77,-79,-83,-84,-86,-89)$ were selected with MapPop (Vision et al. 1999) from a diploid mapping population consisting of $120 \mathrm{~F} 1$ progeny derived from a cross between the diploid parent genotypes SH83-92-488 (SH) and RH89039-16 (RH) (Rouppe van der Voort et al. 1997). This population was previously used to construct an ultra dense genetic map of potato comprising $\sim 10,000$ AFLP-markers divided over approximately 900 bins (Isidore et al. 2003; van Oss et al. 2006; http://www.dpw.wageningen-ur.nl/ uhd/). The genetic bins are defined by single recombination events and correspond to a genetic distance of $0.8 \mathrm{cM}$. For genomic DNA fingerprinting purposes, meristematic leaf material from 5-week old greenhouse plants was lyophilized and genomic DNA was isolated as described by Fulton et al. (1995).

mRNA isolation and cDNA synthesis

RNA was separately isolated from meristematic leaf tissue, stems and roots from eight RHSH genotypes (RHSH\#178, -\#179, -\#185, -58, -60, -71, -84, -86). Material was collected from 5-week old greenhouse plants and immediately frozen in liquid nitrogen. Total RNA was isolated from $1 \mathrm{~g}$ of tissue using TRIZOL ${ }^{\mathrm{TM}}$ (Invitrogen, Breda, The Netherlands) according to the manufacturers' instructions. After isolation, RNA concentrations were estimated by visual inspection on a $1 \%$ agarose gel. Poly- $A^{+}$RNA was 
subsequently extracted from $10 \mu \mathrm{g}$ of total RNA using poly-d[T] $25 \mathrm{~V}$ oligonucleotides coupled to paramagnetic beads (Dynal A.S. Oslo, Norway). cDNA synthesis was carried out as described in Brugmans et al. (2002). Of the final reaction mix (total $50 \mu \mathrm{l}$ ), $5 \mu \mathrm{l}$ was analyzed on a $1 \%$ agarose gel to estimate the final cDNA concentration. All enzymes used were purchased from Invitrogen (Breda, The Netherlands).

NBS profiling using genomic DNA

NBS profiling on genomic DNA was carried out as described by van der Linden et al. (2004). The restriction enzymes MseI, RsaI or HaeIII were used for digestion of genomic DNA. Sequences of the NBS primers used for the amplification of NBS specific fragments are shown in Table 1 together with the corresponding annealing temperatures. For the design of the new primers, protein sequences of NBS regions of $R$ genes and RGAs from potato, tomato and pepper were downloaded from existing remote sequence databases and aligned to each other. Degenerate primers were subsequently designed based on the DNA sequence alignments of conserved P-loop, kinase-2 and GLPL motifs within these sequences (Fig. 1). $\left[\gamma_{-}{ }^{33} \mathrm{P}\right] \mathrm{ATP}-$ labeled PCR products were separated on a $6 \%$ polyacrylamide gel, and the individual fragments were visualized by autoradiography. NBS profiles were generated in duplicate (plant material that was split before DNA extraction and processed in separately performed experiments) for each of

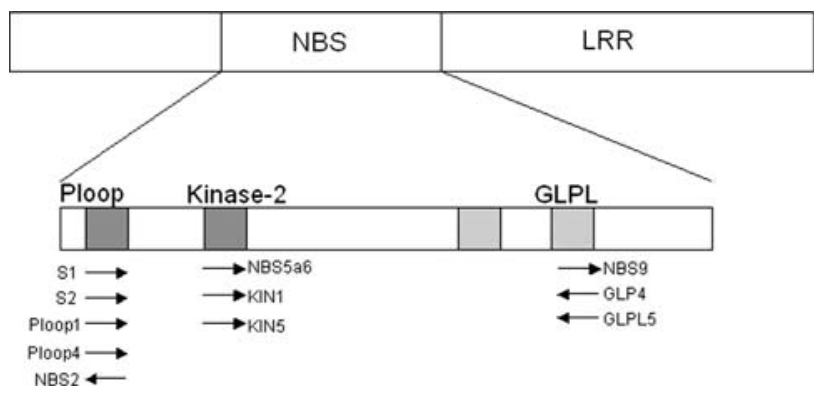

Fig. 1 Relative positions and orientation of primers that target conserved motifs within the NBS region

the $29 \mathrm{~F} 1$ genotypes and the two parental genotypes. Only marker bands that were reproducible in the duplicate samples were scored and added to the existing marker dataset of the UHD map. The relative genetic positions of each candidate RGA marker was calculated using maximum likelihood mapping (van Oss et al. 2006) which allows the mapping of markers relative to the existing UHD map by comparing the marker data with all bin signatures.

\section{NBS profiling using RNA}

For the analysis of $R$ gene transcription in different tissues and between individuals, NBS profiling was performed using cDNA synthesized from mRNA isolated from leaves, roots and stems. NBS profiling with cDNA as template was carried out as described by van der Linden et al. (2004) for
Table 1 NBS specific primer/ enzyme combinations and number of polymorphic RGA bands

\begin{tabular}{|c|c|c|c|c|c|c|}
\hline Primer & Primer sequence & $\mathrm{Ta}$ & Enzyme & $\begin{array}{l}\text { Polymorphic } \\
\text { bands }\end{array}$ & $\begin{array}{l}\text { Reliable } \\
\text { sequences }\end{array}$ & \# RGAs \\
\hline S1 & GGTGGGGTTGGGAAGACAACG & 50 & MseI & 24 & 12 & 4 \\
\hline S2 & GGIGGIGTIGGIAAIACIAC & 50 & MseI & 5 & 2 & 1 \\
\hline Ploop4 & CCGGGITCAGGIAARACWAC & 50 & MseI & 17 & 7 & 5 \\
\hline NBS2 & GTWGTYTTICCYRAICCISSCAT & 55 & MseI & 7 & 6 & 5 \\
\hline NBS2 & GTWGTYTTICCYRAICCISSCAT & 55 & $R s a \mathrm{I}$ & 5 & 4 & 4 \\
\hline NBS2 & GTWGTYTTICCYRAICCISSCAT & 55 & HaeIII & 5 & 2 & 1 \\
\hline $\begin{array}{l}\text { NBS5a } \\
\text { NBS6 }\end{array}$ & $\begin{array}{l}\text { YYTKRTHGTMITKGATGAYGTITGG } \\
\text { YYTKRTHGTMITKGATGATATITGG }\end{array}$ & 55 & MseI & 5 & 4 & 4 \\
\hline $\begin{array}{l}\text { NBS5a } \\
\text { NBS6 }\end{array}$ & $\begin{array}{l}\text { YYTKRTHGTMITKGATGAYGTITGG } \\
\text { YYTKRTHGTMITKGATGATATITGG }\end{array}$ & 55 & $R s a \mathrm{I}$ & 5 & 3 & 3 \\
\hline $\begin{array}{l}\text { NBS5a } \\
\text { NBS6 }\end{array}$ & $\begin{array}{l}\text { YYTKRTHGTMITKGATGAYGTITGG } \\
\text { YYTKRTHGTMITKGATGATATITGG }\end{array}$ & 55 & HaeIII & 6 & 5 & 5 \\
\hline KIN1 & YTKRTTGTIYTIGATGATGTDTGG & 55 & MseI & 15 & 12 & 5 \\
\hline KIN5 & CTTGTMATITTGGATGATGTWTGG & 55 & MseI & 9 & 8 & 6 \\
\hline NBS9 & TGTGGAGGRTTACCTCTAGC & 55 & MseI & 6 & 5 & 4 \\
\hline NBS9 & TGTGGAGGRTTACCTCTAGC & 55 & $R s a \mathrm{I}$ & 8 & 6 & 4 \\
\hline NBS9 & TGTGGAGGRTTACCTCTAGC & 55 & HaeIII & 2 & 2 & 2 \\
\hline GLPL4 & CCCGAAGGAAACCRISRACWARA & 55 & MseI & 15 & 12 & 7 \\
\hline Total & & & & 134 & 90 & 60 \\
\hline
\end{tabular}


genomic DNA. The restriction enzymes MseI or TaqI were used for digestion of the cDNA $(0.4 \mu \mathrm{g})$. The sequences of the NBS specific primers used for the amplification of NBS specific fragments are shown in Table 2 together with the corresponding annealing temperatures. The RGA primers were used in combination with non selective TaqI or MseI primers labeled with the near-infrared fluorescent dye IRD700 to enable visualization on a denaturing polyacrylamide gel using a NEN ${ }^{\circledR} \mathrm{IR}^{2}$ DNA analyser (LI-COR ${ }^{\circledR}$ Biosciences, Lincoln, NE, USA).

Isolation and analysis of NBS fragments

Fragments were excised from polyacrylamide gels using a sharp razor blade, eluted in TE for $5 \mathrm{~min}$ at $100^{\circ} \mathrm{C}$, and reamplified with the NBS specific primer and the adapter primer. In case of LI-COR gels, fragments were excised as described in the Odyssey ${ }^{\circledR}$ manual for 'AFLP band cut out and band extraction' (Westburg, The Netherlands). PCR products were checked on agarose gels and purified with Qiaquick PCR purification spin columns (Qiagen Benelux, The Netherlands). Fragments were either directly sequenced using the adapter primer as a sequencing primer or first cloned into the pGEM-T vector prior to sequencing with T7 or SP6 primers. Sequencing was carried out with the BigDye Terminator kit and an ABI 3700 automated sequencer from Applied Biosystems (USA). Sequences were identified by comparison with entries in the public protein and nucleotide databases using locally installed or remote BLASTX and BLASTN programs (Altschul et al. 1997).

Sequence accession numbers: sequences described in this manuscript will be submitted to Genbank upon acceptance of the paper for publication in TAG.

\section{Results}

Genome-wide RGA mapping

For genome-wide RGA mapping in potato, NBS profiling was performed using 15 primer/enzyme combinations (Table 1) on an informative subset of 29 genotypes from the diploid UHD mapping population as well as the two parental genotypes SH and $\mathrm{RH}$. A total of 134 reproducible polymorphic fragments were subsequently scored. Reproducibility was illustrated by the fact that banding patterns of duplicate samples were identical. For further characterization, all scored fragments were excised from the gel and targeted for sequencing. Of the ninety fragments from which reliable sequence reads were obtained, sixty showed significant similarity to known $R$ genes and RGAs, verifying the RGA nature of the scored fragments. The fragments that were confirmed to be RGA-derived and which showed segregation in the mapping population were mapped relative to the existing UHD dataset, resulting in the genetic mapping of 34 RGA loci, 18 in SH and 16 in RH (Fig. 2). Some loci, e.g. SH2.1, SH6.1, SH10.1, SH11.2 and SH11.3, correspond to loci previously described by Leister et al. (1996) in potato and by Pan et al. (2000) in tomato, both at the sequence level and at the approximate positional level (Table 3; Fig. 2). However, the majority represent either novel RGA loci or novel RGA sequences that map to positions that approximately correspond to those previously described (Fig. 2). Novel RGA loci were identified on chromosome 1 (SH1.1 and RH1.3), chromosome 4 (RH4.1), chromosome 5 (SH5.1 and SH5.2) and chromosome 8 (SH8.1). Loci SH1.1, SH5.1 and SH5.2 share homology to Mi, and RHI.3 to I2 from tomato. RH4.1 and SH4.1 share homology to RGA sequences present on a tomato BAC

Table 2 NBS specific primer/enzyme combinations and the number of fragments generated from the four different classes per primer combination

\begin{tabular}{|c|c|c|c|c|c|c|c|}
\hline Primer & Primer sequence & $\mathrm{Ta}$ & Enzyme & Class 1 & Class 2 & Class 3 & Class 4 \\
\hline Ploop1 & GGIGGINTRGGIAARACRAC & 50 & MseI & 22 & 2 & 1 & 1 \\
\hline Ploop1 & GGIGGINTRGGIAARACRAC & 50 & $\operatorname{Taq} \mathrm{I}$ & 20 & 1 & 2 & 1 \\
\hline Ploop4 & CCGGGITCAGGIAARACWAC & 50 & MseI & 23 & 0 & 3 & 4 \\
\hline Ploop4 & CCGGGITCAGGIAARACWAC & 50 & $\operatorname{Taq} \mathrm{I}$ & 21 & 2 & 2 & 3 \\
\hline KIN1 & YTKRTTGTIYTIGATGATGTDTGG & 55 & MseI & 19 & 2 & 1 & 1 \\
\hline KIN1 & YTKRTTGTIYTIGATGATGTDTGG & 55 & $\operatorname{Taq} \mathrm{I}$ & 21 & 2 & 2 & 3 \\
\hline KIN5 & CTTGTMATITTGGATGATGTWTGG & 55 & MseI & 19 & 1 & 4 & 2 \\
\hline KIN5 & CTTGTMATITTGGATGATGTWTGG & 55 & $\operatorname{Taq} \mathrm{I}$ & 17 & 1 & 2 & 3 \\
\hline GLPL5 & CCKGARGGIRATCGKRRITTTCA & 55 & MseI & 23 & 1 & 3 & 1 \\
\hline GLPL5 & CCKGARGGIRATCGKRRITTTCA & 55 & $\operatorname{Taq} \mathrm{I}$ & 19 & 0 & 2 & 0 \\
\hline Total & & & & 204 & 12 & 22 & 19 \\
\hline
\end{tabular}

Class 1 are fragments amplified with similar intensity between individuals and tissues. Class 2 are fragments with an intensity difference between tissues. Class 3 are fragments with an absent/present difference between tissues and class 4 are fragments with an absent/present difference between individuals 
Fig. 2 Relative positions of putative RGA loci in the UHD map of potato (a SH map, b RH map). Each chromosome is divided into BINS containing varying numbers of cosegregating AFLP markers, indicated by the degree of grey shading (white is 0 and black is $>500$ ). Bars to the right of each chromosome indicate the relative positions of putative RGA loci. Positions of $R$ genes Sen 1-4; H1; $R 3 a / b$; Gpa2/Rx known to segregate in the UHD-population originating from parent $\mathrm{SH}$, the positions of $T m-1$, Q99, Mi, Q173, Tm-2, Sw5, Q133, I2, $Q 136$ from tomato and the positions of R2, Rpi-blb3, Rpi-abpt, Rpi-blb2, Gro1, Rpi-blb1, Gpa6, Sen1, Gpa3, RYsto, Rmc1,

$\mathrm{St} 124, R 1$ from potato are indicated to the left of the chromosomes. Finally all novel RGA loci or novel RGA sequences at known genetic $R$ gene positions are encircled
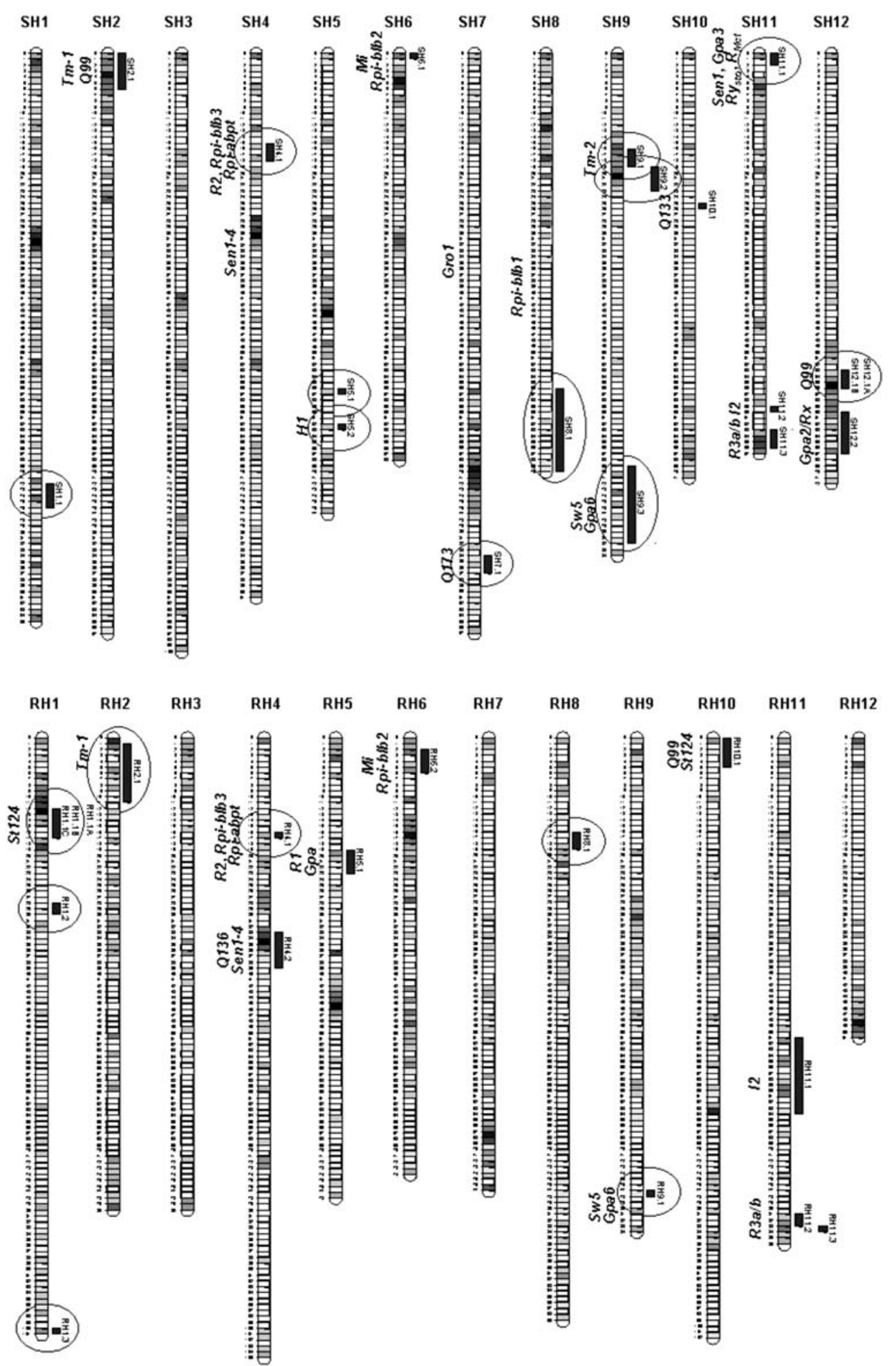

clone (AF411807L; van der Hoeven et al. 2002) and SH8.1 to a putative disease resistance protein (Table 3). Examples of novel RGA sequences which approximately map to previously described loci are RH1.1B/C, SH7.1, SH9.1, SH9.3, $S H 12.1 A$ and SH12.1.B (Fig. 2a). The sequences mapped to RH1.1B/C, SH7.1, SH9.1, SH9.3 and SH12.1A/B share no homology to the syntenous loci $S t 124, Q 173, T m-2, S w 5$ or $Q 99$, respectively.

The potential of the NBS profiling technique for identifying markers linked to functional genes is very well exemplified by the fact that we identified RGA markers linked to all the functional $R$ genes currently mapped in the SHxRH 
Table 3 NBS profiling bands with significant identity to known $R$ genes and RGA cluster members

\begin{tabular}{|c|c|c|c|c|c|}
\hline Locus & BIN (interval) & Primer/enzyme & $\begin{array}{l}\text { Homologue } \\
\text { accession number }\end{array}$ & Annotated function & $\begin{array}{l}\text { Identity-DNA } \\
\text { (length) }\end{array}$ \\
\hline SH1.1 & $73-76$ & GLPL4/MseI & LEU81378 & Mi-1.1 & $94 \%(137)$ \\
\hline $\mathrm{SH} 2.1$ & $1-6$ & PLOOP4/MseI & AF404437 & LeQ99/St124 & $83 \%(382)$ \\
\hline SH4.1 & $16-18$ & NBS5a6/RsaI & AF411807 & LeBAC127E11 (RGA) & $84 \%(246)$ \\
\hline SH5.1 & 57 & NBS5a6/HaeIII & LEU81378 & Mi-1.1 & $90 \%(53)$ \\
\hline SH5.2 & 63 & GLPL4/MseI & AF091048 & Mi-1.1 & $81 \%(94)$ \\
\hline SH6.1 & 1 & NBS5a6/HeaIII & LEU81378 & Mi-1.1 & $86 \%(224)$ \\
\hline SH7.1 & $85-87$ & GLPL4/MseI & AF039681 & Mi-1.1 & $83 \%(133)$ \\
\hline SH8.1 & $57-70$ & Kinase 5/MseI & AC091238 & OzRGA & $51 \%(35 \mathrm{aa})$ \\
\hline SH9.1 & $17-19$ & Kinase1/MseI & AF004879 & $\mathrm{I} 2 \mathrm{C}-2$ & $93 \%(113)$ \\
\hline SH9.2 & $20-23$ & NBS9/MseI & AC249448 & $\mathrm{Rx} 2$ & $93 \%(207)$ \\
\hline SH9.3 & $70-82$ & NBS9/HaeIII & BQ113799 & StEST599375 (RGA) & $94 \%(53)$ \\
\hline SH10.1 & 26 & Kinase 5/MseI & AF404451 & LeQ133 & $94 \%(39)$ \\
\hline SH11.1 & $1-2$ & Kinase $5 / M s e \mathrm{I}$ & AY426260 & BlbRGA3 (Q199) & $97 \%(41)$ \\
\hline SH11.2 & 60 & NBS2/MseI & AF408704 & $\mathrm{I} 2 \mathrm{C}-5$ & $89 \%(157)$ \\
\hline SH11.3 & $64-66$ & NBS2/MseI & AF004878 & I2C-1 & $89 \%(29)$ \\
\hline SH12.1A & $54-56$ & Kinase $5 / M s e \mathrm{I}$ & AF447489 & $\mathrm{R} 1$ & $80 \%(107)$ \\
\hline SH12.1B & $54-56$ & Kinase 5/MseI & AY426261 & BlbRGA3 & $97 \%(42)$ \\
\hline SH12.2 & $61-67$ & NBS9/RsaI & AJ249449 & GPA 2 & $96 \%(88)$ \\
\hline RH1.1A & $13-17$ & $\mathrm{~S} 1 / M s e \mathrm{I}$ & AF404437 & LeQ99 (St124) & $89 \%(107)$ \\
\hline RH1.1B & $13-17$ & PLOOP4/MseI & AF447489 & $\mathrm{R} 1$ & $93 \%(265)$ \\
\hline RH1.1C & $13-17$ & PLOOP4/MseI & LEU65667 & $\mathrm{Mi}$ & $93 \%(252)$ \\
\hline RH1.2 & $29-30$ & NBS9/MseI & AF266747 & RGC1 (Gpa2/Rx) & $82 \%(272)$ \\
\hline RH1.3 & 101 & PLOOP4/MseI & AF004878 & I2C-1 & $92 \%(156)$ \\
\hline RH2.1 & $2-11$ & S1/MseI & AY187296 & MeRCa6 & $65 \%(32 \mathrm{aa})$ \\
\hline RH4.1 & 17 & $\mathrm{NBS} 2 / R s a \mathrm{I}$ & AF411807 & LeBAC127E11 (RGA) & $78 \%(157)$ \\
\hline RH4.2 & $34-39$ & Kinase1/MseI & AF404454 & LeQ136 (I2C-2) & $93 \%(182)$ \\
\hline RH5.1 & $20-23$ & NBS5a6/HaeIII & AF447489 & $\mathrm{R} 1$ & $96 \%(258)$ \\
\hline RH6.1 & $3-6$ & Ploop/MseI & AF039681 & Mi-1.1 & $85 \%(170)$ \\
\hline RH8.1 & $17-19$ & NBS9/RsaI & AF195939 & Gpa2 & $79 \%(309)$ \\
\hline RH9.1 & 78 & NBS9/HaeIII & BQ113799 & StEST599375 (RGA) & $94 \%(53)$ \\
\hline RH10.1 & $1-5$ & Kinase5/MseI & AF404437 & LeQ99 (St13) & $91 \%(171)$ \\
\hline RH11.1 & $52-64$ & Kinase1/MseI & AF404456 & LeQ138 (I2C-1) & $93 \%(64)$ \\
\hline RH11.2 & $82-83$ & S1/MseI & STU60069 & St11 & $84 \%(125)$ \\
\hline RH11.3 & $84-86$ & NBS5a6/RsaI & AF004878 & $\mathrm{I} 2 \mathrm{C}-1$ & $95 \%(48)$ \\
\hline cDNA-01 & Class $4^{\mathrm{a}}$ & Kinase1/TaqI & AF404434 & LeQ95 & $90 \%(369)$ \\
\hline cDNA-02 & Class $2^{\mathrm{a}}$ & Kinase1/TaqI & AJ457050 & Hero3 & $89 \%(331)$ \\
\hline cDNA-03 & Class $3^{\mathrm{a}}$ & Kinase5/TaqI & STU60074 & St125 & $99 \%(249)$ \\
\hline cDNA-04 & Class $1^{\mathrm{a}}$ & Kinase1/TaqI & AR29071 & BlbRGA3 & $48 \%(56)$ \\
\hline cDNA-05 & Class $4^{\mathrm{a}}$ & Kinase1/TaqI & STU60069 & St11 & $85 \%(95)$ \\
\hline cDNA-06 & Class $1^{\mathrm{a}}$ & PLOOP1/TaqI & LE25SRIB & Tomato $25 \mathrm{~S}$ ribosomal RNA gene & $96 \%(129)$ \\
\hline cDNA-07 & Class $4^{\mathrm{a}}$ & PLOOP1/TaqI & AF534298 & LhS2_410 (RGA) & $83 \%(75)$ \\
\hline cDNA-08 & Class $2^{\mathrm{a}}$ & PLOOP4/TaqI & AJ716167 & Sc_TNBS1-45 (RGA) & $98 \%(112)$ \\
\hline cDNA-09 & Class $4^{\mathrm{a}}$ & Kinase1/TaqI & AF516615 & FRGA-A30 (RGA) & $96 \%(350)$ \\
\hline cDNA-10 & Class $3^{\mathrm{a}}$ & Kinase 5/TaqI & AF404437 & LeQ99 & $93 \%(71)$ \\
\hline cDNA-11 & Class $3^{\mathrm{a}}$ & Kinase 5/TaqI & AF404431 & LeQ88 & $72 \%(58)$ \\
\hline cDNA-12 & Class $1^{\mathrm{a}}$ & Kinase 5/TaqI & AAF04603 & Gpa2 & $58 \%(43)$ \\
\hline
\end{tabular}

${ }^{a}$ fragments not mapped, instead indicated to which class the fragment belongs 
population using only a limited set of RGA specific primers. On chromosome 5, SH5.2 corresponds to the same genetic interval as the nematode resistance locus $H 1$ which in SH has been mapped to SHBIN63 (Bakker et al. 2004). On chromosomes 11 and 12, SH11.3 and SH12.2 correspond to intervals that harbor the late blight resistance genes $R 3 a$ and $R 3 b$ (SHBIN65; Huang et al. 2004) and the nematode resistance gene Gpa2 (SHBIN67; Rouppe van der Voort et al. 1999; van der Vossen et al. 2000), respectively. Moreover, alignment of the BIN maps of SH4 and $\mathrm{RH} 4$ reveals that $R H 4.2$ corresponds to the genetic interval on SH4 to which the wart disease resistance locus Sen 1-4 has been mapped (SHBIN37-41; Brugmans et al. 2006). Although Sen 1-4 is derived from SH, BIN numbers of RH4 correspond well with those of $\mathrm{SH} 4$, as is illustrated by the putative positions of the centromere (BIN35 in RH4 and BIN31 in SH4). Interestingly, locus SH4.2 corresponds both at the nucleotide and positional level to Q136 from tomato which shares high homology to $I 2 C$-2 (Table 3).

\section{NBS profiling using cDNA}

The results presented in this paper clearly show the potential of NBS profiling in producing markers in RGA sequences, and in both known resistance loci and putatively new resistance loci. However, it is not clear whether the markers actually target functional $R$ genes. For isolation and cloning of a functional $R$ gene, NBS profiling on genomic DNA represents only a first step. However, it should be possible to select against markers derived from non-functional (pseudo) genes by using cDNA as a template for NBS profiling rather than genomic DNA. In an attempt to validate this idea NBS profiling was performed on cDNA generated from RNA derived from different tissues. In total ten primer/enzyme combinations (Table 2) were tested on a subset of eight genotypes from the diploid UHD mapping population. Typical profiling patterns, comprising 20-35 bands, obtained with leaf, root or stem tissue specific cDNAs, are shown in Fig. 3. The majority of the fragments (204) amplified using the ten primer/enzyme combinations were monomorphic (class 1 ) and did not show marker variation in intensity between genotypes or between the different tissues. Based on putative differences in transcription in the analyzed tissues and between genotypes, the remaining fragments can be grouped into three different classes (Fig. 3). First there are intensity polymorphisms between the different tissues derived from one genotype (class 2). Absent/present polymorphisms between the different tissues, while the transcription between individuals is similar form class 3 . The last class contains absent/present polymorphisms between genotypes while transcription is present in the same tissues (class 4). In total 53 fragments showed segregation. Of these, 22 showed clear absent/

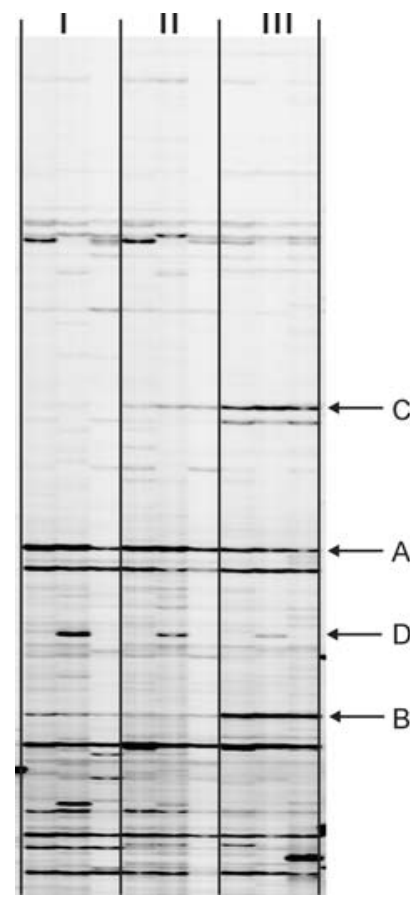

Fig. 3 A section of a representative NBS profiling LI-COR image using Kin $1 /$ TaqI as primer/enzyme combination. The banding pattern was generated from cDNA of leaves (I) stems (II) and roots (III) of three different individuals of an F1 mapping population. $A$ no intensity polymorphisms between tissues or individuals (class 1 ); $B$ intensity polymorphism between tissues (class 2); $C$ present/absent polymorphism between tissues (class 3); $D$ absent/present polymorphism between individuals (class 4)

present differences between tissues and 19 were absent/ present polymorphisms between genotypes. The other 12 were intensity differences between tissues (Table 2).

For further characterization 19 fragments including at least two fragments of each class were excised from the gel and targeted for sequencing. Of the 12 bands that produced a readable sequence, all but one showed significant similarity to known $R$ genes and RGAs, confirming the RGA nature of the majority of the fragments (Table 3 ).

\section{Discussion}

Sequence information generated through large scale genome and EST sequencing efforts has lead to the development of candidate gene based marker technologies. One of these applications is the NBS profiling technique (van der Linden et al. 2004) which specifically targets RGAs. In the current study we have used (degenerate) NBS specific primers to amplify a multi-locus RGA marker pattern from both genomic DNA and cDNA. To verify the origin of the amplified fragments, a total of 134 genomic DNA derived and 19 cDNA derived fragments were sequenced, of which 90 genomic DNA and 12 cDNA derived fragments gave a 
readable sequence. Of these 102 sequences, 60 genomic DNA and 11 cDNA derived fragments shared high homology with $R$ gene or RGA specific sequences confirming that the majority of the amplified fragments were truly derived from RGAs. This is in agreement with the findings of van der Linden et al. (2004) who found that the majority of the fragments amplified by NBS profiling using different potato genotypes were RGA derived.

By combining the marker data of the 60 segregating RGA fragments with the data of the UHD genetic map of potato, it was possible to genetically map these markers relative to 10,000 AFLP markers. By using the most informative subset $(n=29)$ of the diploid F1 SHxRH mapping population the accuracy of the map position was reduced to an average interval of five bins (Table 3). Due to the lack of marker data for individuals that show recombination within this interval, more accurate mapping is not possible. Nevertheless, the resolution is sufficient to indicate the approximate genetic region in which the marker and thus an $R$ gene locus is located. Furthermore, it is known which genotypes of the UHD mapping population have undergone recombination within any interval of interest and thus can be used to increase the resolution within the interval.

In a comparative study of genomic organization of $R$ genes and RGAs in tomato, potato and pepper, Grube et al. (2000) observed, in contrast with the findings of Leister et al. (1998) for Gramineae, significant conservation of $R$ gene loci, despite limited positional correspondence of phenotypically defined genes conferring resistance to related or identical pathogens. This suggests that the chromosomal locations of $R$ gene clusters is broadly conserved through speciation, and that comparative genomics can be an instrument for rapid identification of genes that are structurally similar to those already mapped in related genera. Our results indicate that, although many $R$ gene clusters are indeed conserved between potato and tomato, many may be part of heterogeneous superclusters which harbor more than a single RGA family. For Arabidopsis, it was reported that $\sim 10 \%$ of the NBS-LRR clusters contained NBS-LRR genes of diverse subgroups but that these clusters are likely the result of random associations among the 149 NBSLRR-encoding genes in the Arabidopsis Col-0 genome (Meyers et al. 2003). For tomato Pan et al. (2000) also found genetic linkage between NBS containing $R$ gene sequences from different origin. The genetic mapping of these sequences in tomato was based upon a set of inbred lines giving a low marker resolution and thus a large genetic interval in which the markers could be placed. Although the genetic resolution of our mapping in the UHD map is higher compared to the study by Pan et al. (2000), it is still too low to draw conclusions on the physical clustering of NBS-LRR genes from different origin from our NBS profiling mapping data.
Functional $R$ genes are expected to be continuously transcribed in the tissues that might be infected by a pathogen. Therefore NBS profiling was performed using cDNA derived from RNA extracted out of plants that were not inoculated or triggered towards a defense response to detect functional $R$ genes. Although few $R$ genes have been shown to be induced upon pathogen infection, $R$ gene related ESTs have in some cases been identified only in pathogen challenged libraries (Ronnings et al. 2003). Transcription levels of the target genes are therefore expected to be low, which could lead to problems related to PCR kinetics and sensitivity (Vos et al. 1998). However, when using the standard NBS profiling protocol as developed by van der Linden et al. (2004), between 20 and 35 fragments were amplified, which is approximately half the number of bands typically amplified with NBS profiling on genomic DNA, suggesting that NBS profiling is suitable to analyse the expression of relatively low expressed genes, although further exploration of the limits of detection of NBS profiling, e.g. through QRT-PCR analysis, is required to support this conclusion. Furthermore, a series of tissues was analyzed from different genotypes, making it possible to detect putative tissue-specific transcription and to compare putative tissue specific fragments between genotypes. Fragments that segregated between genotypes could also be evaluated for their reproducibility between tissues. The fact that no major differences were detected within or between the genotypes depending on the class of transcription, underlines the reproducibility of the technique. This is in agreement with the results found for DNA whereby NBS profiling was performed twice upon the same DNA. Although the data presented here suggest that RGAs and/or $R$ genes may be transcribed at different levels in different tissues, further analysis of transcriptional differences at different time points in development and in different environments will shed further light on this interesting subject.

As is possible when profiling genomic DNA, it is also possible to detect absent/present polymorphisms when profiling cDNA and to genetically map these markers (Brugmans et al. 2002). cDNA based NBS-profiles showed some clear absent/present polymorphisms between $\mathrm{F} 1$ genotypes. However, because the number of F1 genotypes used was only eight, it was not possible to genetically map the generated absent/present polymorphisms relative to the complete population $(n=130)$ or the subset $(n=29)$ used for the mapping of DNA derived RGA-fragments. When this NBS profiling is repeated using more individuals of this population, it will be possible to genetically map the polymorphic fragments relative to the genetic markers of the UHD mapping population leading to the identification of transcribed $R$ gene clusters. For the fragments that are differentially transcribed between tissues, sequence information can help to develop SCAR or other kinds of PCR based markers, 
which can be used for the genetic mapping and possible cloning of tissue specific $R$ genes. Comparison of the complete sequences of the different tissue specific RGA's with each other and with the RGA's transcribed in all tissues, might lead to a better understanding of the functional regions and the mechanisms underlying the resistance response against the different types of pathogens.

The gene-for-gene interaction between the $\mathrm{R}$ protein of a plant and the Avr protein of the pathogen is thought to be highly specific. For some $R$ genes, for example $M i$, it was found that the same $R$ gene confers resistance against different pathogens (Vos et al. 1998, Nombela et al. 2003) implying that $R$ genes can function in different tissues. This assumption is supported by the findings of van der Vossen et al. (2000) who reported about a resistance-gene cluster in potato containing genes with high homologies, but resistance to distinct pathogens affecting different plant tissues. Our results indicate that many $R$ genes are in fact transcribed in multiple tissues. The majority of the amplified fragments in the NBS profiles with cDNA from different tissues were amplified in all tissues examined. Still ten percent of the fragments were amplified only in one or two tissues. Approximately $5 \%$ of the fragments gave clear intensity differences between tissues. In total approximately $15 \%$ of the NBS profiling fragments showed transcription differences between tissues, possibly reflecting differences in $R$ gene specificity. Tissue-specific transcription differences may underlie tissue-specific resistance reactions against the same pathogen (e.g. Phytophthora resistance in tubers and leaves). NBS profiling therefore provides a tool with which the genes involved in such a reaction can be identified and located. The observed putative tissue specificity of RGA transcription would imply that the promoter used to drive transcription of a specific $R$ gene upon transformation can have its effect on the phenotype and thus the results of the complementation test. Therefore it is advisable to try and simulate nature as much as possible by using the native promoter of an $R$ gene.

In search for markers linked to resistance genes both RNA and DNA can be used in combination with NBS profiling resulting in a high number of RGA derived fragments. For both RNA and DNA, fragments can be generated that show segregation between individuals which can be mapped relative to other markers of an existing genetic map. The number of verifiable RGA derived fragments from RNA was 11 out of 12 whereas for DNA 60 out of 90 sequenced fragments were confirmed to be RGA derived. Although this suggests that DNA is more sensitive for mispriming, resulting in the amplification of polymorphic DNA sequences that are not derived from RGA's, this conclusion has to be verified by analyzing equal amounts of cDNA and genomic DNA derived fragments from the same primer/enzyme combination. The only cDNA fragment which was not RGA derived was a fragment that was amplified out of all samples and all tissues with the same intensity and appeared to be ribosomal RNA derived.

For the detection and cloning of a specific $R$ gene of interest, the most suitable template is cDNA compared to genomic DNA, due to the fact that cDNA only contains transcribed genes and thus leads to the detection of fragments derived from putatively functional genes. Furthermore, it might also be possible to amplify $R$ gene derived fragments using NBS profiling by using cDNA isolated from 'primed' tissue which is challenged for a specific $R$ gene reaction, leading directly to the $R$ gene of interest. On the other hand, genomic DNA as template is easier to handle and the average percentage of polymorphic fragments found using genomic DNA is much higher than for cDNA, therefore genomic DNA is a better option to use as template for genome wide mapping of RGA's and RGA rich regions. Also for the detection of markers closely linked to an $R$ gene but not necessarily derived from the gene itself (e.g. to use for QTL analysis or marker assisted selection in a breeding program) genomic DNA is more suitable as template than cDNA. Irrespective of the choice of template, NBS profiling is a good option for the generation of markers linked to RGA's.

Open Access This article is distributed under the terms of the Creative Commons Attribution Noncommercial License which permits any noncommercial use, distribution, and reproduction in any medium, provided the original author(s) and source are credited.

\section{References}

Altschul S, Madden T, Schäffer A, Zhang J, Zhang Z, Miller W, Lipman D (1997) Gapped BLAST and PSI-BLAST: a new generation of protein database search programs. Nucleic Acids Res 25:3389-3402

Bakker E, Achenbach U, Bakker J, van Vliet J, Peleman J, Segers B, van der Heijden S, van der Linden P, Graveland R, Hutten R, van Eck H, Coppoolse E, van der Vossen E, Bakker J, Goverse A (2004) A high-resolution map of the H1 locus harbouring resistance to the potato cyst nematode Globodera rostochiensis. Theor Appl Genet 109:146-152

Brugmans B, Fernandez del Carmen A, Bachem CWB, van Os H, van Eck HJ, Visser RGF (2002) A novel method for the construction of genome wide transcriptome maps. Plant J 31:211-222

Brugmans B, Hutten RGB, Rookmaker NO, Visser RGF, van Eck HJ (2006) Exploitation of a marker dense linkage map of potato for positional cloning of a wart disease resistance gene. Theor Appl Genet 112:269-77

Calenge F, van der Linden CG, van de Weg E, Schouten HJ, van Arkel G, Denancé C, Durel CE (2005) Resistance gene analogues identified through the NBS profiling method map close to major genes and QTL for disease resistance in apple. Theor Appl Genet 110:660-668

Flor H (1971) Current status of the gene-for-gene concept. Annu Rev Phytopathol 9:275-296

Fulton TM, Chunwongse J, Tanksley SD (1995) Microprep protocol for extraction of DNA from tomato and other herbaceous plants. Plant Mol Biol Rep 13:207-209 
Gebhardt C, Valkonen JPT (2001) Organization of genes controlling disease resistance in the potato genome. Annu Rev Phytopathol 39:79-102

Goff SA, Ricke D, Lan TH, Presting G, Wang R, Dunn M, Glazebrook J, Sessions A, Oeller P, Varma H, Hadley D, Hutchison D, Martin C, Katagiri F, Lange BM, Moughamer T, Xia Y, Budworth P, Zhong J, Miguel T, Paszkowski U, Zhang S, Colbert M, Sun WL, Chen L, Cooper B, Park S, Wood TC, Mao L, Quail P, Wing R, Dean R, Yu Y, Zharkikh A, Shen R, Sahasrabudhe S, Thomas A, Cannings R, Gutin A, Pruss D, Reid J, Tavtigian S, Mitchell J, Eldredge G, Scholl T, Miller RM, Bhatbagar S, Adey N, Rubano T, Tusneem N, Robinson R, Feldhaus J, Macalma T, Oliphant A, Briggs S (2002) A draft sequence of the rice genome (Oryza sativa L. ssp. Japonica). Science 296:92-100

Grube RC, Radwanski ER, Jahn M (2000) Comparative genetics of disease resistance within the solanaceae. Genetics 155:873-887

Hayes AJ, Saghai Maroof MA (2000) Targeted resistance gene mapping in soybean using modified AFLPs. Theor Appl Genet 100:1279-1283

Huang S, Vleeshouwers VGAA, Werij JS, Hutten RCB, van Eck HJ, Visser RGF, Jacobsen E (2004) The R3 Resistance to phytophthora infestans in potato is conferred by two closely linked $R$ genes with distinct specificities. Plant Microbe Interact 17:428-435

Hunger S, Di Gaspero G, Möhring S, Bellin D, Schafer-Pregel R, Borchardt DC, Durel C, Werber M, Weisshaar B, Salamini F, Schneider K (2002) Isolation and linkage analysis of expressed disease-resistance gen analogues of sugar beet (Beta vulgaris L.). Genome 46:70-82

Isidore E, Van Os H, Andrzejewski S, Bakker J, Barrena I, Bryan GJ, Buntjer J, Caromel B, Van Eck HJ, Ghareeb B, De Jong W, Van Koert P, Lefebvre V, Milbourne D, Ritter E, Rouppe van der Voort JNAM, Rousselle-Bourgeois F, Van Vliet J, Waugh R (2003) Toward a marker-dense meiotic map of the potato genome: lessons from linkage group I. Genetics 165(4):2107-2116

Kanazin V, Marek LF, Shoemaker RC (1996) Resistance gene analogs are conserved and clustered in soybean. Proc Natl Acad Sci USA 93:11746-11750

Keen NT (1990) Gene-for-gene complementarity in plant-pathogen interactions. Annu Rev Genet 24:447-463

Kuhn DN, Heath M, Wisser RJ, Meerow A, Brown JS, Lopes U, Schnell RJ (2003) Resistance gene homologues in Theobroma cacao as useful genetic markers. Theor Appl Genet 107:191-202

Leister D, Ballvora A, Salamini F, Gebhardt C (1996) A PCR-based approach for isolating pathogen resistance genes from potato with potential for wide application in plants. Nat Genet 14:421-429

Leister D, Kurth J, Laurie DA, Yano M, Sasaki T, Devos K, Graner A, Schulze-Lefert P (1998) Rapid reorganization of resistance gene homologues in cereal genomes. Proc Natl Acad Sci USA 95:370 375

Martin GB, Bogdanove AJ, Sessa G (2003) Understanding the function of plant disease resistance proteins. Annu Rev Plant Biol 54:23-61

Meyers BC, Morgante M, Michelmore RW (2002) TIR-X and TIRNBS proteins: two new families related to disease resistance TIRNBS-LRR proteins encoded in Arabidopsis and other plant genomes. Plant J 32:77-92

Meyers BC, Kozik A, Griego A, Kuang H, Michelmore RW (2003) Genome-wide analysis of NBS-LRR-encoding genes in Arabidopsis. Plant Cell 15:809-834

Milligan SB, Bodeau J, Yaghoobi J, Kaloshian I, Zabel P, Williamson VM (1998) The root knot nematode resistance gene $M i$ from tomato is a member of the leucine zipper, nucleotide binding, leucine-rich repeat family of plant genes. Plant Cell 10:1307-1319

Nombela G, Williamson V, Muniz M (2003) The root-knot nematode resistance gene $\mathrm{Mi}-1.2$ of tomato is responsible for resistance against the whitefly Bremisia tabaci. MPMI 16:645-649

Pan Q, Liu Y, Budai-Hadrian O, Sela M, Carmal-Goren L, Zamir D, Fluhr R (2000) Comparative genetics of nucleotide binding siteleucine rich repeat resistance gene homologues in the genomes of two dicotyledons: tomato and Arabidopsis. Genetics 155:309322

Ronnings CM, Stegalkina SS, Ascenzi RA, Bougri O, Hart AL, Utterbach TR, Vanaken SE, Riedmuller SB, White JA, Cho J, Pertea GM, Lee Y, Karamycheva S, Sultana R, Tsai J, Quackenbush J, Griffiths HM, Restrepo S, Smart CD, Fry WE, van der Hoeven R, Tanksley S, Zhang P, Jin H, Yamamoto ML, Baker BJ, Buell CR (2003) Comparative analyses of potato expressed sequence tag libraries. Plant Physiol 131:419-429

Rossi M, Goggin FL, Milligan SB, Kaloshian I, Ullman DE, Williamson VM (1998) The nematode resistance gene $M i$ of tomato confers resistance against the potato aphid. Proc Natl Acad Sci USA 95:9750-9754

Rouppe van der Voort J, Wolters P, Folkertsma R, Hutten R, Van Zandvoort P, Vinke H, Kanyuka K, Bendahmane A, Jacobsen E, Janssen R, Bakker J (1997) Mapping of the cyst nematode resistance locus $\mathrm{Gpa} 2$ in potato using a strategy based on comigrating AFLP markers. Theor Appl Genet 95:874-880

Shen KA, Meyers BC, Islam/Faridi MN, Chin DB, Stelly DM, Mitchelmore RW (1998) Resistance gene candidates identified by PCR with degenerate oligonucleotide primers map to clusters of resistance genes in lettuce. Mol Plant Microbe Interact 11:815823

The Arabidopsis Genome Initiative (TAGI) (2000) Analysis of the genome sequence of the flowering plant Arabidopsis thaliana. Nature 6814:796-815

van der Linden G, Wouters D, Mihalka V, Kochieva E, Smulders M, Vosman B (2004) Efficient targeting of plant disease resistance loci using NBS profiling. Theor Appl Genet 109:384-393

van der Vossen E, van der Voort J, Kanyuka K, Bendahmane A, Sandbrink H, Baulcombe D, Bakker J, Stiekema W, Klein-Lankhorst $\mathrm{R}$ (2000) Homologues of a single resistance-gene cluster in potato confers resistance to distinct pathogens: a virus and a nematode. Plant J 23:567-576

van Oss H, Andrzejewski S, Bakker E, Barrena I, Bryan G, Caromal B, Ghareeb B, Isidore E, de Jong W, van Koert P, Lefebre V, Milbourne D, Ritter E, Rouppe van der Voort J, Rousselle-Bourgeois F, van Vliet J, Waugh R, Visser J, van Eck H (2006) Construction of a 10, 000-marker ultradense genetic recombination map of potato: providing a framework for accelerated gene isolation and a genomewide physical map. Genetics 173:1075-1087

Vision TJ, Brown DG, Shmoys DB, Durrett RT, Tanksley SD (1999) Selective mapping: a strategy for optimizing the construction of high-density linkage maps. Genetics 155:407-420

Vos P, Simons G, Jesse T, Wijbrandi J, Heinen L, Hogers R, Frijters A, Groenendijk J, Diergaarde P, Reijans M, Fierens-Onstenk J, de Both M, Peleman J, Liharska T, Hontelez J, Zabeau M (1998) The tomato $M i-1$ gene confers resistance to both root-knot nematodes and potato aphids. Nat Biotechnol 16:1365-1369

Yu YG, Saghai Buss GR, Maroof MA (1996) Isolation of a superfamily of candidate disease-resistance genes in soybean based on a conserved nucleotide-binding site. Proc Natl Acad Sci USA 93:11751-11756 